\title{
Comorbidity between DSM-IV alcohol use disorders and major depression: results of a national survey
}

\author{
Bridget F. Grant*, Thomas C. Harford \\ Division of Biometry and Epidemiology, Suite 514, National Institute on Alcohol Abuse and Alcoholism, 6000 Executive Blvd. MSC 7003 , \\ Bethesda, MD 20892-7003, USA
}

Received 30 March 1995; accepted 26 June 1995

\begin{abstract}
The purpose of this study was to describe detailed patterns of comorbidity between Diagnostic and Statistical Manual of Mental Disorders - Fourth Edition (DSM-IV) alcohol use disorders and major depression using a representative sample of the United States. Comorbidity rates and associations between DSM-IV alcohol use disorders and major depression were expressed as odds ratios with confidence intervals adjusted for the complex design characteristics of the NLAES. Comorbidity analyses were presented by sex, ethnicity and age for past year, prior to past year and lifetime diagnoses. Virtually all odds ratios were significantly greater than 1.0, demonstrating that comorbidity of alcohol use disorders and major depression is pervasive in the general population. The magnitude of the association remained stable across the three time frames but diagnostic and subgroup variations in comorbidity were noted. The association between alcohol dependence and major depression was greater than the association between abuse and major depression and the association between alcohol abuse and major depression was consistently greater for females and blacks, compared to their male and non-black counterparts. Implications of the results are discussed in terms of professional help seeking, the self-medication hypothesis, and differential social control theory.
\end{abstract}

Keywords: Comorbidity; Alcohol use disorders; Major depression; Comorbid disorder

\section{Introduction}

The co-occurrence of alcohol use disorders and major depression has frequently been reported in alcoholic and psychiatric patients samples (Allen and Francis, 1986; Demitio, 1989; Keeler et al., 1979; Petty, 1992). Research conducted in treated samples has also highlighted the clinical relevance of such comorbidity as adversely affecting the course, treatment and prognosis of both alcohol use disorders and major depression (Keitner et al., 1991; Pottenger et al., 1978; Rounsaville et al., 1987). However, studies of patients in treatment are not well suited to the study of the distribution of comorbidity, since patterns of comorbidity found in clinical samples are not representative of those found in the general pop-

\footnotetext{
* Corresponding author.
}

ulation. Individuals in treatment are more likely to have multiple disorders than cases in the general population, (Ross et al., 1988; Rounsaville et al., 1991; Wolf et al., 1988) thus spuriously inflating estimates of the prevalence of comorbidity (Berkson, 1946).

General population surveys designed to reliably study the distribution of comorbidity are rare. To date, only two major studies have considered psychiatric comorbidity, including alcohol use disorders and major depression, in the United States. The first was the Epidemiologic Catchment Area (ECA) Survey, (Robins et al., 1991), in which 18571 respondents were interviewed in a series of five community-based epidemiologic studies in the early $1980 \mathrm{~s}$. The second was the National Comorbidity Survey (NCS), a nationally representative sample of 8098 respondents conducted in 1991 (Kessler et al., 1994). 
The purpose of the present report was to present detailed descriptive epidemiological data on the association between alcohol use disorders and major depression in the third and most recent national comorbidity study of 42862 respondents, the National Institute on Alcohol Abuse and Alcoholism's (NIAAA) National Longitudinal Alcohol Epidemiologic Survey (NLAES) (Grant et al., 1994; Massey et al., 1989). Several methodological advantages of the NLAES and its psychiatric assessment instrument are noteworthy. First, the diagnostic interview used in the NLAES, the Alcohol Use Disorder and Associated Disabilities Interviews Schedule (Grant and Hasin, 1992) yielded diagnoses based on the most current psychiatric classification or the Diagnostic and Statistical Manual of Mental Disorders - Fourth Edition (DSM-IV; American Psychiatric Association, 1992) and/not its predecessors, the Third Edition Revised (DSM-III-R; American Psychiatric Association, 1987) used in the NCS or the Third Edition (DSM-III; American Psychiatric Association, 1980) used in the ECA. Second, unlike the NLAES, the ECA was not a nationally representative sample of the United States population and the relatively small sample size of the NCS could not provide for reliable and detailed analyses of comorbidity among major subgroups of the population defined by sex, ethnicity or age. This is a serious limitation since clinical studies have shown comorbidity rates to vary by important sociodemographic variables (Roy et al., 1991a, 1991b; Woodruff et al., 1979).

One of the unique aspects of the AUDADIS was its syndromal measurement of alcohol use disorders as defined in the DSM-IV. The Diagnostic Interview Schedule (DIS; Robins et al., 1981) used in the ECA and the University of Michigan-Composite International Diagnostic Interview (UM-CIDI; Wittchen and Kessler, 1991) used in the NCS both failed to measure the syndromal aspects of alcohol use disorders as defined by the DSM-III and DSM-III-R. For example, to achieve a DIS and UM-CIDI lifetime diagnosis of DSM-III or DSM-III-R alcohol dependence, a respondent only needed to report two or three positive dependence symptoms, respectively, over the entire life course. In both interviews, only one positive symptom was necessary to meet diagnostic criteria for an alcohol abuse diagnosis on a lifetime basis. Similarly, the DIS and UM-CIDI defined current or past year alcohol dependence as meeting the criteria for a lifetime diagnosis with the occurrence of at least one dependence symptom during the past year, Unlike the DIS and UM-CIDI, the AUDADIS alcohol use disorders are represented syndromally, that is, as the clustering of enough symptoms of abuse or dependence at the same time to achieve a diagnosis. Alcohol use disorders are defined for three time frames in the AUDADIS, the past year, prior to the past year and on a lifetime basis. It is important to note the AUDADIS redefined the current operation alization of lifetime diagnosis as described in the ECA and NCS. With the AUDADIS, the prevalence of lifetime diagnosis was now defined as the occurrence of an episode of either alcohol abuse or dependence at any time in a respondent's life, rather than a loose collection of abuse or dependence symptoms accumulating over the life course.

The NLAES overcomes many of the methodological problems inherent in the ECA and NCS, including, sampling difficulties and small sample sizes, the lack of current definitions of alcohol use disorders and major depression, the absence of detailed comorbidity analyses among important subgroups of the population, and the failure to represent alcohol use disorders as syndromes. Thus, the basic comorbidity rates and associations between alcohol use disorders and major depression derived from the NLAES are likely to be more reliable and precise than those reported from either the ECA and NCS.

\section{Methods}

\subsection{Study sample}

Prevalence and comorbidity estimates of DSM-IV alcohol use disorders and major depression were based on the 1992 NLAES, a national probability survey sponsored by the NIAAA. Field work for the study was conducted by the United States Bureau of the Census. Direct face-to-face interviews were conducted with 42862 respondents, 18 years of age and older residing in the non-institutionalized population of the contiguous United States, including the District of Columbia. The household response rate was $91.9 \%$ and the sample person response rate was $97.4 \%$.

The NLAES featured a complex multistage design (Grant et al., 1994). Primary sampling units (PSUs) were stratified according to sociodemographic criteria and were selected with probability proportional to size. From a sampling frame of approximately 2000 PSUs, 198 were selected for inclusion in the 1992 NLAES sample, including 52 which were self representing - that is, selected with certainty. Within PSUs, geographically defined secondary sampling units, referred to as segments, were selected systematically for sample. Oversampling of the black population was accomplished at this stage of sample selection to secure adequate numbers for analytic purposes. Segments then were divided into clusters of approximately 4-8 housing units, and all occupied housing units were included in NLAES. Within each household, 1 randomly selected respondent, 18 years of age or older, was selected to participate in the survey. Oversampling of young adults, 18-29 years of age, was accomplished at this stage of the sample selection to include a greater representation of this heavy drinking population subgroup. This sub- 
group of young adults was randomly sampled at a ratio of $2.25 \%$ to $1.00 \%$.

\subsection{Diagnostic assessment}

Diagnoses of DSM-IV alcohol use disorders and major depression were derived from the AUDADIS, a fully-structured psychiatric interview designed to be administered by trained interviewers who were not clinicians. The AUDADIS included an extensive list of symptom questions that operationalized the DSM-IV criteria for alcohol use disorders and major depression. These questions are described in detail elsewhere (Grant et al., 1994). Although the DSM-IV was not published until 1994, the specific diagnostic criteria of interest were known prior to the conduct of the NLAES (American Psychiatric Association, 1991) and, therefore, incorporated in their entirety within the AUDADIS. In an independent test-retest study conducted in the general population AUDADIS diagnoses of alcohol use disorders and major depression were shown to be highly reliable achieving reliability $(\alpha)$ coefficients ranging between $0.73-0.76$ and $0.60-0.65$ for the various time frames, respectively (Grant et al., 1995).

Consistent with the DSM-IV, an AUDADIS diagnosis of alcohol abuse required that a person exhibit a maladaptive pattern of alcohol use, leading to clinically significant impairment or distress, as demonstrated by at least one of the following in any one year: (1) continuing to drink despite a social or interpersonal problem caused or exacerbated by the effects of drinking; (2) recurrent drinking in situations in which alcohol use is physically hazardous; (3) recurrent drinking resulting in a failure to fulfil major role obligations; or (4) recurrent alcohol-related legal problems. An AUDADIS diagnosis of alcohol dependence required that a person meet at least 3 of 7 criteria defined for dependence in any 1 year including: (1) tolerance; (2) withdrawal or relief or avoidance of withdrawal; (3) persistent desire or unsuccessful attempts to cut down or stop drinking; (4) spending much time drinking or recovering from its effects; (5) giving up or reducing occupational, social or recreational activities in favor of drinking; (6) impaired control over drinking; and (7) continuing to drink despite a physical or psychological problem caused or exacerbated by drinking.

Unlike the DIS and UM-CIDI, the AUDADIS diagnoses of alcohol abuse and dependence also satisfied the clustering or duration criteria of the DSMIV definition. In the DSM-III, the duration criterion associated with abuse and dependence specified each disturbance to persist for at least 1 month, a requirement not met in the DIS. In the DSM-III-R, the duration or clustering criterion for symptoms was directly applied to the categories of alcohol abuse and dependence (i.e. some symptoms of the disorder needed to occur consistently for at least a month or repeatedly over a longer period of time). This aspect of the DSMIII-R definition of abuse and dependence was ignored in the UM-CIDI. In contrast, the duration criteria of the DSM-IV included the requirement for a clustering of symptoms within any 1 year period, in addition to associating duration qualifiers with certain abuse and dependence symptoms. The duration qualifiers are defined as the repetitiveness with which symptoms must occur in order to be counted as positive towards a diagnosis. They are represented by the terms 'recurrent', 'often' and 'persistent' appearing in the diagnostic criteria.

Not only were the duration criteria represented in past year AUDADIS diagnoses of abuse and dependence, but the corresponding prior to the past year diagnoses were also measured as syndromes, or the clustering of the required number of symptoms necessary to achieve a diagnosis. The method used to establish the clustering of symptoms for prior to the past year diagnoses was that of recapitulation. This entails the summarization of symptoms occurring in the past by the interviewer who then separately determines through a series of additional questions whether the required number of symptoms of abuse and dependence occurred at the same time in the past or either (1) continuously for a month or longer, (2) repeatedly over the period of a month or longer. Respondents classified with a lifetime diagnosis encompassed all those who had ever experienced an episode of abuse or dependence, in the past year and/or prior to the past year rather than those demonstrating the required number of symptoms of these disorders over the life course.

Episodes of DSM-IV major depressive disorder were also constructed for the past prior to the past year, and lifetime in order to allow for comorbidity analyses within each time frame. Consistent with the DSM-IV, the AUDADIS diagnoses of major depression required the presence of at least 5 depressive symptoms (inclusive of depressed mood or loss of pleasure and interest) nearly every day for most of the day for at least the same 2 week period. In contrast to the DSM-III-R definition of major depression, social and/or occupational dysfunction must also have been present during the disturbance, and episodes of DSM-IV major depression exclusively due to bereavement and physical illness were ruled out.

\subsection{Statistical analysis}

Because of the complex survey design of the NLAES, variance estimation procedures that assume a simple random sample cannot be employed. Statistical research has shown that clustering and stratification specifications of the NLAES sample may result, in certain instances, in standard errors somewhat larger than those that would be obtained with a simple random sample of equal size (Massey et al., 1989). To take into account the NLAES sample design, all standard errors of the preva- 
lence estimates and comorbidity rates (expressed as weighted percentages) presented here were generated using SUDAAN, (Research Triangle Institute, 1994) a software program that uses Taylor series linearization to adjust for sample design characteristics.

Associations between alcohol use disorders and major depression were expressed in terms of odds ratios. Odds ratios and their $95 \%$ confidence intervals were derived from separate logistic regression analyses using the SUDAAN LOGISTIC program that also adjusted for the complex sampling design of the NLAES. An odds ratio of greater than 1.0 reflects a positive association between the comorbid disorders and is statistically significant if its $\mathbf{9 5 \%}$ confidence intervals does not encompass the value of 1.0. An odds ratio of 1.0, or indistinguishable from 1.0 as bounded by the $95 \%$ confidence intervals, was considered non-significant.

It is important to note that the present analyses focused on what has been termed episode or period comorbidity, or the co-occurrence of two or more psychiatric disorders at the same time or during the same interval. Episode comorbidity should be contrasted with comorbidity viewed from the primary-secondary distinction in which one of two or more comorbid disorders is designated as primary, usually on the basis of its first occurrence or onset at an earlier age. An important consequence of examining the co-occurrence of disorders from a period comorbidity perspective, rather than a primary-secondary perspective is that the odds ratios are equivalent regardless of whether alcohol use disorders or major depression is designated as the index or focal disorder.

\section{Results}

\subsection{Prevalence rates}

Table 1 shows the prevalence rates of DSM-IV major depression for each of the three time frames and by each sex, ethnic and age subgroup of the population in which comorbidity rates were examined. Nearly $10.0 \%$ of the respondents had a history of major depression, with $3.33 \%$ and $7.73 \%$ having an episode in the past 12 months and prior to that time, respectively. Rates of major depression in the past year, prior to the past year and lifetime were $29.4 \%, 19.7 \%$ and $21.3 \%$ greater among females than males. Rates among non-blacks also exceeded those of their black counterparts by $25.6 \%$

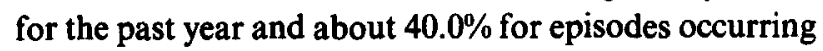
prior to the past year and on a lifetime basis. Prevalences of major depression decreased with age within each time frame.

The prevalences of DSM-IV alcohol abuse and dependence are summarized in Table 2 by sex, ethnicity and age according to the time of occurrence of the episode. The prevalence of combined abuse and dependence was $18.17 \%$ on a lifetime basis, with $7.41 \%$ and $14.60 \%$ of the
Table 1

Prevalence of DSM-IV major depression by sex, ethnicity and age United States, 1992

\begin{tabular}{lllr}
\hline $\begin{array}{l}\text { Sociodemo- } \\
\text { graphic } \\
\text { characteristic }\end{array}$ & $\begin{array}{l}\text { Past year } \\
\%(\text { S.E. }\end{array}$ & $\begin{array}{l}\text { Prior to past } \\
\text { year \% (S.E.) }\end{array}$ & \multicolumn{1}{c}{$\begin{array}{l}\text { Lifetime } \\
\%(S . E .)\end{array}$} \\
\hline Total & $3.33(0.10)$ & $7.73(0.16)$ & $9.86(0.18)$ \\
Sex & & & \\
Male & $2.74(0.16)$ & $6.85(0.23)$ & $8.64(0.26)$ \\
Female & $3.88(0.14)$ & $8.54(0.21)$ & $10.99(0.23)$ \\
& & & \\
Ethnicity & & $4.65(0.35)$ & $6.52(0.41)$ \\
Black & $2.55(0.25)$ & $8.13(0.18)$ & $10.29(0.19)$ \\
Non-black & $3.43(0.11)$ & & \\
& & $10.38(0.33)$ & $14.28(0.39)$ \\
Age & & $9.48(0.31)$ & $11.87(0.34)$ \\
18-29 years & $5.99(0.27)$ & $6.79(0.30)$ & $8.00(0.32)$ \\
30-44 years & $3.86(0.18)$ & $1.50(0.16)$ & $1.79(0.17)$ \\
45-64 years & $1.80(0.14)$ & & \\
65+ years & $0.55(0.09)$ & & \\
\hline
\end{tabular}

respondents experiencing an episode within the previous year and prior to that time, respectively. Slightly more respondents were classified as meeting DSM-IV criteria for dependence rather than abuse, a pattern consistent for all three time frames and among each sociodemographic subgroup of the population. Regardless of time frame examined, the prevalence of abuse and dependence was greater among males than females, greater among non-blacks compared to blacks, and generally decreased with age.

\subsection{Comorbidity}

Table 3 shows the comorbidity rates and associations between alcohol abuse and dependence combined, and separately for abuse and dependence and major depression for the three time frames of interest. The analyses shown in Table 3 assume that major depression represents the exposed group with the odds ratios representing the odds of an alcohol use disorder in the exposed group relative to the odds in the unexposed group or among those with no major depression. Among respondents with an episode of major depression in the past year, $21.36 \%$ were additionally classified with an alcohol abuse or dependence diagnosis compared to $6.92 \%$ of the respondents with no evidence of major depression during this time period. Regardless of time frame, the increased risk of having an alcohol use disorder among those with major depression was about 4 times (ORs $=3.65-3.89$ ) greater than those without major depression. The association between alcohol dependence and major depression was stronger than the association between alcohol abuse and major depression. The odds of abuse among respondents with major 


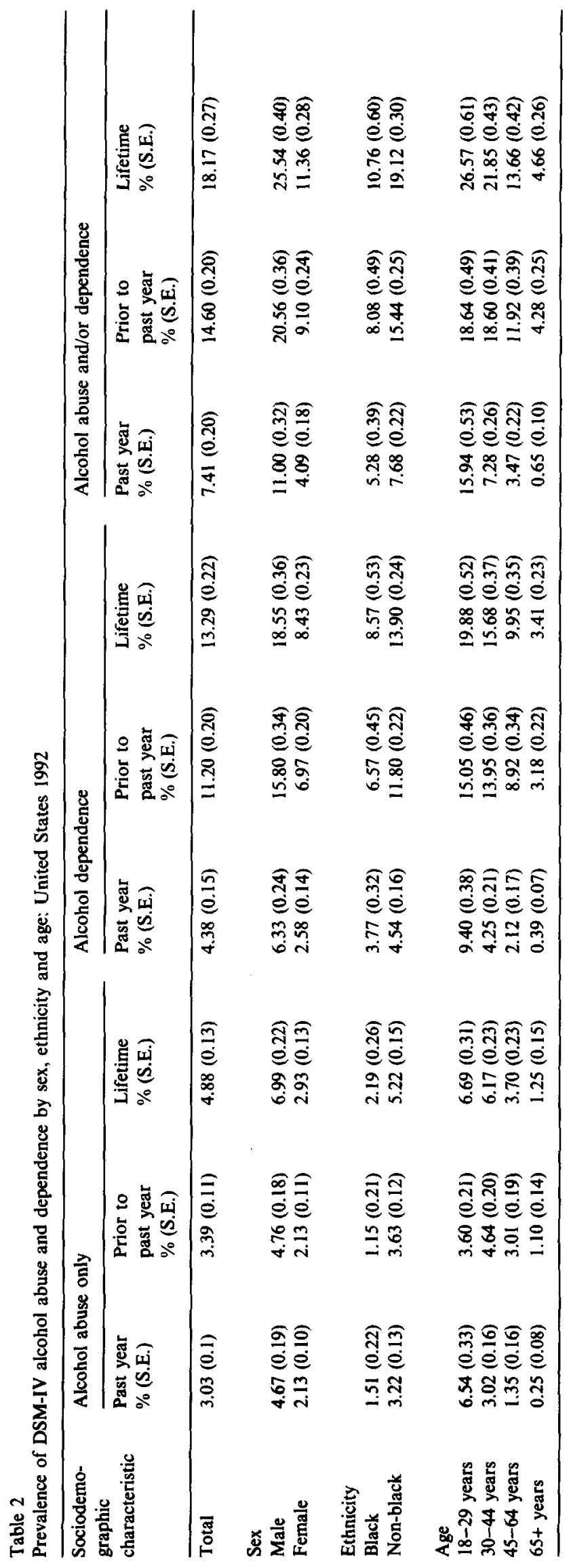


Table 3

Prevalence and odds ratios of DSM-IV alcohol abuse and dependence and DSM-IV major depression by time frame: United States, 1992

\begin{tabular}{|c|c|c|c|c|}
\hline Alcohol use disorder & $\begin{array}{l}\text { Major depression } \\
\% \text { (S.E.) }\end{array}$ & $\begin{array}{l}\text { No major depression } \\
\% \text { (S.E.) }\end{array}$ & Odds ratio & $\begin{array}{l}\text { (95\% Confidence } \\
\text { limits) }\end{array}$ \\
\hline \multicolumn{5}{|c|}{ Past year } \\
\hline Abuse and/or dependence & $21.36(1.38)$ & $6.92(0.19)$ & 3.65 & $(3.12,4.27)$ \\
\hline Abuse only & $6.31(0.74)$ & $2.92(0.11)$ & 2.24 & $(1.74,2.88)$ \\
\hline Dependence & $15.05(1.23)$ & $4.01(0.14)$ & 4.24 & $(3.51,5.13)$ \\
\hline \multicolumn{5}{|c|}{ Prior to past year } \\
\hline Abuse and/or dependence & $36.31(0.58)$ & $12.78(0.22)$ & 3.89 & $(3.55,4.27)$ \\
\hline Abuse only & $6.26(0.49)$ & $3.15(0.11)$ & 2.05 & $(1.71,2.46)$ \\
\hline Dependence & $30.05(0.99)$ & $9.63(0.19)$ & 4.03 & $(3.65,4.45)$ \\
\hline \multicolumn{5}{|c|}{ Lifetime } \\
\hline Abuse and/or dependence & $40.03(0.95)$ & $15.78(0.26)$ & 3.56 & $(3.29,3.86)$ \\
\hline Abuse only & $7.54(0.44)$ & $4.59(0.13)$ & 1.69 & $(1.49,1.94)$ \\
\hline Dependence & $32.49(0.90)$ & $11.19(0.20)$ & 3.82 & $(3.51,4.16)$ \\
\hline
\end{tabular}

Table 4

Past year prevalence and odds ratios of DSM-IV alcohol abuse and dependence and DSM-IV major depression by sex, ethnicity and age: United States, 1992

\begin{tabular}{|c|c|c|c|}
\hline Alcohol use disorder & $\begin{array}{l}\text { Major depression } \\
\% \text { (S.E.) }\end{array}$ & $\begin{array}{l}\text { No major depression } \\
\% \text { (S.E.) }\end{array}$ & $\begin{array}{l}\text { Odds ratio ( } 95 \% \\
\text { Confidence limits) }\end{array}$ \\
\hline \multicolumn{4}{|c|}{ Male } \\
\hline Abuse and/or dependence & $34.55(2.48)$ & $10.33(0.30)$ & $4.58(3.69,5.69)$ \\
\hline Abuse only & $9.17(1.42)$ & $4.54(0.20)$ & $2.12(1.49,3.02)$ \\
\hline Dependence & $25.38(2.39)$ & $5.79(0.23)$ & $5.54(4.31,7.12)$ \\
\hline \multicolumn{4}{|c|}{ Female } \\
\hline Abuse and/or dependence & $12.75(1.26)$ & $3.74(0.17)$ & $3.76(3.01,4.69)$ \\
\hline Abuse only & $4.44(0.76)$ & $1.40(0.09)$ & $3.28(2.28,4.72)$ \\
\hline Dependence & $8.31(9.98)$ & $2.34(0.13)$ & $3.78(2.91,4.89)$ \\
\hline \multicolumn{4}{|c|}{ Black } \\
\hline Abuse and/or dependence & $12.14(3.15)$ & $5.10(0.40)$ & $2.57(1.41,4.69)$ \\
\hline Abuse only & $5.93(2.50)$ & $1.40(0.20)$ & $4.45(1.78,11.14)$ \\
\hline Dependence & $6.21(2.14)$ & $3.71(0.32)$ & $1.72(1.01,3.63)$ \\
\hline \multicolumn{4}{|c|}{ Non-black } \\
\hline Abuse and/or dependence & $22.25(1.47)$ & $7.16(0.21)$ & $3.71(3.15,4.36)$ \\
\hline Abuse only & $6.34(0.78)$ & $3.11(0.12)$ & $2.11(1.62,2.74)$ \\
\hline Dependence & $15.90(1.32)$ & $4.05(0.15)$ & $4.48(3.70,5.44)$ \\
\hline \multicolumn{4}{|c|}{$18-29$ years } \\
\hline Abuse and/or dependence & $30.58(2.23)$ & $15.01(0.51)$ & $2.49(2.03,3.07)$ \\
\hline Abuse only & $10.52(1.47)$ & $6.28(0.33)$ & $1.75(1.27,2.41)$ \\
\hline Dependence & $20.07(1.93)$ & $8.72(0.38)$ & $2.63(2.05,3.36)$ \\
\hline \multicolumn{4}{|c|}{$30-44$ years } \\
\hline Abuse and/or dependence & $15.78(1.83)$ & $6.94(0.26)$ & $2.51(1.90,3.33)$ \\
\hline Abuse only & $2.90(0.71)$ & $3.03(0.16)$ & $1.04(0.63,1.72)$ \\
\hline Dependence & $12.88(1.74)$ & $3.91(0.21)$ & $3.63(2.63,5.03)$ \\
\hline \multicolumn{4}{|c|}{$45-64$ years } \\
\hline Abuse and/or dependence & $9.19(2.02)$ & $3.36(0.22)$ & $2.91(1.77,4.76)$ \\
\hline Abuse only & $2.74(1.05)$ & $1.32(0.15)$ & $2.10(0.94,4.70)$ \\
\hline Dependence & $6.45(1.76)$ & $2.04(0.17)$ & $3.31(1.83,5.97)$ \\
\hline \multicolumn{4}{|c|}{$65+$ years } \\
\hline Abuse and/or dependence & - & - & - \\
\hline Abuse only & - & - & - \\
\hline Dependence & - & - & - \\
\hline
\end{tabular}

Note: Past year prevalences of major depression among 65+ year old respondents was too low for reliable estimation of comorbidity rates. 
depression was $\sim 2$ times greater than those experiencing no major depression within each time frame.

Tables 4-6 present comorbidity rates and associated odds ratios of alcohol use disorders among those with and without a co-occurring major depression for each time frame separately for each sex, ethnic and age subgroup of the population. The risk of alcohol abuse and major depression was consistently greater among females and blacks compared to their male and non-black counterparts, respectively. The opposite was true, to a lesser extent, for the association between dependence and major depression. Males and non-blacks demonstrated a greater association between alcohol dependence and major depression than either females or blacks, respectively, particularly within the past year and on a lifetime basis. Although not entirely consistent for abuse only diagnoses, the odds ratios associated with dependence and combined abuse and dependence had a tendency to increase with age most predominantly in terms of lifetime comorbidity.

\section{Discussion}

The most striking result from this study was that virtually all the odds ratios were significantly greater than 1.0, demonstrating that the comorbidity of alcohol use disorders and major depression is pervasive in the general population. The results largely confirm, in a general population sample, a number of reports in the literature conducted in clinical samples. Among those with a current or past year alcohol use disorder, $9.61 \%$ experienced a major depression, a comorbidity rate significantly greater than the population base rate of current major depression (3.33\%). Conversely, $21.36 \%$ of the

Table 5

Prior to past year prevalence and odds ratios of DSM-IV alcohol abuse and dependence and DSM-IV major depression by sex, ethnicity and age: United States, 1992

\begin{tabular}{|c|c|c|c|}
\hline Alcohol use disorder & $\begin{array}{l}\text { Major depression } \\
\% \text { (S.E.) }\end{array}$ & $\begin{array}{l}\text { No major depression } \\
\% \text { (S.E.) }\end{array}$ & $\begin{array}{l}\text { Odds ratio } \\
\text { (95\% Confidence limits) }\end{array}$ \\
\hline \multicolumn{4}{|c|}{ Male } \\
\hline Abuse and/or dependence & $49.51(1.73)$ & $18.43(0.36)$ & $4.34(3.76,5.01)$ \\
\hline Abuse only & $8.17(0.91)$ & $4.51(0.18)$ & $1.88(1.47,2.42)$ \\
\hline Dependence & $41.33(1.63)$ & $13.62(0.32)$ & $4.36(3.79,5.01)$ \\
\hline \multicolumn{4}{|c|}{ Female } \\
\hline Abuse and/or dependence & $26.55(1.10)$ & $7.47(0.22)$ & $4.48(3.97,5.06)$ \\
\hline Abuse only & $4.84(0.52)$ & $1.87(0.11)$ & $2.66(2.07,3.42)$ \\
\hline Dependence & $21.71(1.08)$ & $5.59(0.18)$ & $4.68(4.08,5.37)$ \\
\hline \multicolumn{4}{|c|}{ Black } \\
\hline Abuse and/or dependence & $25.09(3.16)$ & $7.26(0.47)$ & $4.27(3.02,6.06)$ \\
\hline Abuse only & $3.88(1.67)$ & $1.39(0.21)$ & $2.86(1.13,7.25)$ \\
\hline Dependence & $21.20(2.97)$ & $5.87(0.43)$ & $4.32(3.00,6.27)$ \\
\hline \multicolumn{4}{|c|}{ Non-black } \\
\hline Abuse and/or dependence & $37.14(1.08)$ & $13.52(0.24)$ & $3.78(3.43,4.16)$ \\
\hline Abuse only & $6.43(0.52)$ & $3.39(0.12)$ & $1.96(1.63,2.36)$ \\
\hline Dependence & $30.70(1.05)$ & $10.13(0.20)$ & $3.93(3.54,4.36)$ \\
\hline \multicolumn{4}{|c|}{$18-29$ years } \\
\hline Abuse and/or dependence & $39.89(1.69)$ & $16.18(0.48)$ & $3.44(2.96,3.99)$ \\
\hline Abuse only & $5.60(0.80)$ & $3.36(0.21)$ & $1.70(1.23,2.37)$ \\
\hline Dependence & $34.00(1.65)$ & $12.82(0.46)$ & $3.55(3.02,4.17)$ \\
\hline \multicolumn{4}{|c|}{$30-44$ years } \\
\hline Abuse and/or dependence & $38.36(1.58)$ & $16.53(0.40)$ & $3.14(2.73,3.62)$ \\
\hline Abuse only & $7.73(0.80)$ & $4.32(0.21)$ & $1.86(1.46,2.37)$ \\
\hline Dependence & $30.62(1.51)$ & $12.21(0.34)$ & $3.17(2.73,3.69)$ \\
\hline \multicolumn{4}{|c|}{$45-64$ years } \\
\hline Abuse and/or dependence & $30.50(1.94)$ & $10.57(0.39)$ & $3.71(3.06,4.51)$ \\
\hline Abuse only & $5.25(1.04)$ & $2.84(0.19)$ & $1.89(1.23,2.91)$ \\
\hline Dependence & $25.05(1.81)$ & $7.73(0.33)$ & $4.03(3.28,4.96)$ \\
\hline \multicolumn{4}{|c|}{$65+$ years } \\
\hline Abuse and/or dependence & $12.82(1.13)$ & $4.15(0.25)$ & $3.40(1.94,5.95)$ \\
\hline Abuse only & $1.44(0.86)$ & $1.09(0.14)$ & $1.32(0.26,6.66)$ \\
\hline Dependence & $11.38(2.94)$ & $3.06(0.22)$ & $4.07(2.26 .7 .35)$ \\
\hline
\end{tabular}


Table 6

Lifetime prevalence and odds ratios of DSM-IV alcohol abuse and dependence and DSM-IV major depression by sex, ethnicity and age: United States, 1992

\begin{tabular}{|c|c|c|c|}
\hline Alcohol use disorder & Major depression \% (S.E.) & No major depression $\%$ (S.E.) & Odds ratio $(95 \%$ \\
\hline \multicolumn{4}{|c|}{ Male } \\
\hline Abuse and/or dependence & $55.21(1.50)$ & $22.74(0.40)$ & $4.19(3.69,4.76)$ \\
\hline Abuse only & $9.97(0.85)$ & $6.71(0.23)$ & $1.54(1.27,1.87)$ \\
\hline Dependence & $45.24(1.46)$ & $16.03(0.34)$ & $4.33(3.83,4.89)$ \\
\hline \multicolumn{4}{|c|}{ Female } \\
\hline Abuse and/or dependence & $29.02(1.03)$ & $9.18(0.26)$ & $4.04(3.63,4.51)$ \\
\hline Abuse only & $5.78(0.46)$ & $2.58(0.13)$ & $2.14(1.92,2.79)$ \\
\hline Dependence & $23.25(0.97)$ & $6.60(0.21)$ & $4.28(3.79,4.84)$ \\
\hline \multicolumn{4}{|c|}{ Black } \\
\hline Abuse and/or dependence & $25.54(2.57)$ & $9.73(0.60)$ & $3.18(2.38,4.25)$ \\
\hline Ábuse only & $4.64(1.43)$ & $2.02(0.26)$ & $2.36(1.20,4.66)$ \\
\hline Dependence & $20.89(2.39)$ & $7.71(0.53)$ & $3.16(2.31,4.32)$ \\
\hline \multicolumn{4}{|c|}{ Non-black } \\
\hline Abuse and/or dependence & $41.22(1.01)$ & $16.59(0.28)$ & $3.52(3.24,3.84)$ \\
\hline Abuse only & $7.77(0.47)$ & $4.93(0.15)$ & $1.62(1.42,1.86)$ \\
\hline Dependence & $33.44(0.96)$ & $11.66(0.22)$ & $3.81(3.40,1.17)$ \\
\hline \multicolumn{4}{|c|}{$18-29$ years } \\
\hline Abuse and/or dependence & $45.70(1.51)$ & $23.38(0.63)$ & $2.75(2.42,3.15)$ \\
\hline Abuse only & $8.62(0.79)$ & $6.37(0.33)$ & $1.39(1.11,1.73)$ \\
\hline Dependence & $37.08(1.47)$ & $17.01(0.52)$ & $2.88(2.50,3.30)$ \\
\hline \multicolumn{4}{|c|}{$30-44$ years } \\
\hline Abuse and/or dependence & $40.88(1.41)$ & $19.29(0.42)$ & $2.89(2.56,3.27)$ \\
\hline Abuse only & $7.87(0.69)$ & $5.94(0.24)$ & $1.35(1.10,1.66)$ \\
\hline Dependence & $33.01(1.33)$ & $13.35(0.36)$ & $3.20(2.81,3.64)$ \\
\hline \multicolumn{4}{|c|}{$45-64$ years } \\
\hline Abuse and/or dependence & $32.24(1.82)$ & $12.04(0.42)$ & $3.48(2.91,4.15)$ \\
\hline Abuse only & $5.89(1.00)$ & $3.51(0.23)$ & $1.72(1.19,2.49)$ \\
\hline Dependence & $26.35(1.70)$ & $8.53(0.35)$ & $3.84(3.18,4.64)$ \\
\hline \multicolumn{4}{|c|}{$65+$ years } \\
\hline Abuse and/or dependence & $13.30(2.86)$ & $4.50(0.26)$ & $3.25(2.00,5.36)$ \\
\hline Abuse only & $1.20(0.78)$ & $1.25(0.15)$ & $1.05(0.54,5.26)$ \\
\hline Dependence & $12.10(2.72)$ & $3.25(0.22)$ & $4.10(2.43,6.89)$ \\
\hline
\end{tabular}

respondents with major depression reported an alcohol use disorder during the past year, a comorbidity rate significantly greater than the population base rate of alcohol abuse and dependence combined (7.41\%). These comorbidity rates are consistent with, but lower, than those reported in treatment samples $(8.0-53.0 \%$ ), suggesting that the comorbidity among alcohol use disorders and major depression is related to professional help seeking.

The associations between lifetime depression and lifetime alcohol use disorders were $3.56,1.69$ and 3.82 for alcohol abuse and dependence combined, alcohol abuse only and alcohol dependence, respectively. The corresponding lifetime ratios reported in the ECA $(O R s=1.3,0.9$ and 1.6) were not statistically significant
(Regier et al., 1990). Although not strictly comparable, the risks found for comorbid alcohol use disorders and major depression during the past year $(O R=3.65)$ exceeded the corresponding 6-month odds ratios reported from the ECA (OR = 2.7) and NCS (OR = 2.6) (Kessler et al., 1995; Regier et al., 1990). These findings may result from a variety of factors that preclude direct comparisons between surveys, including differences in sampling frame and sample size, diagnostic interview schedules, or diagnostic criteria used to formulate diagnoses. Alternatively, the AUDADIS representation of alcohol use disorders as syndromes, as opposed to alcohol symptoms occurring over the life course derived from the DIS or UM-CIDI, could, in part, be responsible for the higher comorbidity rates observed in the 
present study. That is, the AUDADIS measurement of alcohol use disorders as cohesive constellations of symptoms clustering within specified time frames, might be more highly associated with other psychiatric disorders also measured as syndromes, than are operationalization of alcohol use disorders as loose collections of alcohol symptoms accumulating over the life course.

There was little variation in comorbidity rates and odds ratios across the three time frames of interest. This stability is consistent with evidence from clinical studies that alcohol is often used to self-medicate major depression. Specifically, the mood effects of alcohol have been shown to be variable, initially causing euphoria but producing dysphoria particularly with prolonged use among chronic users. The similarity of the odds ratios associated with past year and lifetime diagnoses, and prior to the past year and lifetime diagnoses suggests that self-medication for depression with alcohol may be effective in the short term but that chronic, prolonged self-medication may lead to increased dysphoria and exacerbation of depressive symptoms in the long-term. If self-medication was successful in the long-term, we would have expected the association to be lower in the past year time frame relative to the lifetime and prior to the past year time frames. Alternatively, these findings suggest that having a comorbid diagnosis may impede recovery from either disorder through a mechanism other than self-medication. More conclusive evidence supporting the self-medication or other hypothesis must await the reanalysis of NLAES data from a primary secondary comorbidity perspective, as opposed to the episodic comorbidity perspective presented here.

Although the relationship between alcohol dependence and major depression was greater than the abusemajor depression association at the aggregate level, subgroup variation in the strength of the abuse and dependence relationships with major depression were noted. There was a slight trend for the magnitude of the association between alcohol use disorders and major depression to increase with age for prior to the past year and lifetime diagnoses. These findings may reflect age differences in the lifetime risk of both alcohol use disorders and major depression.

The associations between alcohol abuse and major depression were also consistently greater across time frames among females and blacks compared to their male and non-black counterparts, respectively. One reason for this observed risk differential may be implicated in the definition of abuse underlying the comorbidity rates. The DSM-IV defines alcohol abuse, separately from dependence, as social, occupational, legal and interpersonal consequences arising from drinking. Indicators of patterns of compulsive drinking (e.g. impaired control over drinking, giving up important activities to drink) and tolerance and withdrawal symptomatology were relegated to the dependence category. Unlike the physiological and compulsive use indicators of DSM-IV dependence, the DSM-IV abuse criteria may be viewed as societal reactions to drinking behavior. As socially subordinate subgroups of the population, female's and black's drinking behavior may be more heavily sanctioned than that of males and non-blacks, (Makela, 1987; Park, 1983), thereby increasing their vulnerability to societal reaction as reflected in the DSM-IV formulation of alcohol abuse. The increased risk of major depression among females and blacks diagnosed as alcohol abusers, may therefore reflect the development of major depression among these subgroups of the population as the result of a more adverse societal reaction to their drinking behavior than experienced by either males or non-blacks.

Although the results of the present study have answered basic questions about the descriptive epidemiology of episode comorbidity in the general population, future research using the NLAES data will focus on differentiating competing hypotheses or models underlying the comorbidity of alcohol use disorders and major depression. Central to this research was the measurement of age of onset of each disorder that would allow comorbidity analyses from a primary and secondary perspective. The AUDADIS uniquely provides for this requirement particularly in its measurement of age of onset of episodes of alcohol use disorders as opposed to age of onset of the first symptom of abuse or dependence. Despite the need for longitudinal studies of comorbidity that are eminently more suited to elucidate causes, recent advances in multivariate statistical procedures (e.g. survival analysis, structural equation modelling combined with logistic regression) will enable testing of competing causal hypotheses underlying comorbidity with this retrospective data.

The consistent and significant associations between major depression and alcohol use disorder shown in this study provides persuasive evidence that major depression must be addressed as a critical component of alcohol abuse and dependence prevention efforts. Early recognition and appropriate treatment of major depression should be a promising addition to the battery of existing prevention strategies for alcohol abuse and dependence. With regard to the treatment implications, tailoring alcohol programs to individuals with mood (and other psychiatric disorders) and substance use disorders should facilitate meeting the specific management needs of this important subgroup of comorbid individuals. From a scientific perspective, future research on comorbidity should be encouraged and supported with a view that the study of the interrelationships between two or more disorders may help elucidate the causes of both.

\section{References}

Allen, M.H. and Francis, R.J. (1986) Varieties of psychopathology found in patients with affective disorders: A review. In: 
Psychopathology and Addictive Disorders, (Meyer, R.E., ed.), pp. 86-102. Guilford Press, New York.

American Psychiatric Association. (1980) Diagnostic and Statistical Manual of Mental Disorders - Third Edition. American Psychiatric Association, Washington, DC.

American Psychiatric Association. (1987) Diagnostic and Statistical Manual of Mental Disorders - Third Edition - Revised. American Psychiatric Association, Washington, DC.

American Psychiatric Association. (1991) DSM-IV Options Book. American Psychiatric Association, Washington, DC.

American Psychiatric Association. (1994) Diagnostic and Statistical Manual of Mental Disorders - Fourth Edition. American Psychiatric Association, Washington, DC.

Berkson J. (1946) Limitations of the application of the 4-fold table analyses to hospital data. Biometrics. 2, 47-53.

Demilio, L. (1989) Psychiatric syndromes in adolescent substance abusers. Am. J. Psychiat. 146, 1212-1214.

Grant, B.F., Dawson, D.A., Chou, S.P. and Pickering, R. (1994) Source and Accuracy Statement for the National Longitudinal Alcohol Epidemiologic Survey. National Institute on Alcohol Abuse and Alcoholism, Rockville, MD.

Grant, B.F., Peterson Harford, T.C., Dawson, D.A. and Chou, S.P. and Pickering, R.P. (1994) Prevalence of DSM-IV alcohol abuse and dependence: United States, 1992. Alcohol Health Res. World $18,243-248$.

Grant, B.F., Harford, T.C., Dawson, D.A., Chou, S.P. and Pickering, R.P. (1995) The Alcohol Use Disorders and Associated Disabilities Schedule (AUDADIS): Reliability of Alcohol and Drug Modules in a General Population Sample. Alcohol Drug Depend. In press.

Grant, B.F. and Hasin, D.S. (1992) The Alcohol Use Disorders and Associated Disabilities Interview Schedule. National Institute on Alcohol Abuse and Alcoholism, Rockville, MD.

Keeler, M.H., Taylor, C.I. and Miller, W.C. (1979) Are all recently detoxified alcoholics depressed? Am. J. Psychiat. 136, 586-588.

Keitner, G.I., Ryan, C.E., Miller, I.W., Kohn, R. and Epstein, N.B. (1991) 12-month outcome of patients with major depression and comorbid psychiatric and medical illness. Am. J. Psychiat. 148, 345-350.

Kessler, R.C., Mc Gonagle, K.A., Camelley, K.B., Nelson, C.B., Fanner, M.E. and Regier, D.A. (1995) The epidemiology of psychiatric comorbidity. In: Textbook of Psychiatric Epidemiology, (Tsaung, M., Cohen, M. and Zahner, G., eds.). John Wiley and Sons, New York. In press.

Kessler, R.C., Mc Gonagle, K.A. and Shanyang, Z. (1994) Lifetime and 12-month prevalence of DSM-III-R psychiatric disorders in the United States: Results from the National Comorbidity Survey. Arch. Gen. Psychiat. 51, 8-19.

Makela, K. (1987) Level of consumption and social consequences of drug. In: Recent Advances in Alcohol and Drug Problems, (Israel, Y., Glaser, F. and Popham, R., eds.), Plenum Press, New York.

Massey, J.T., Moore, T.F., Parsons, R.P. and Tadros, W. (1989) Design and Estimation from the National Health Interview Survey, 1985-1994. National Center for Health Statistics, Hyattsville, MD.
Park, P. (1983) Social class factors in alcoholism. In: The Pathogenesis of Alcoholism: Psychosocial Factors, (Kissin, B. and Begleiter, H., eds.). Plenum Press, New York.

Petty, F. (1992) The depressed alcoholic: clinical features and medical management. Gen. Hosp. Psychiat. 14, 258-264.

Pottenger, M., McKemon, J., Patrie, L.E., Weissman, M.M., Rubin, H.L. and Newberry, P. (1978) The frequency and persistence of depressive symptoms in the alcohol abuser. J. Nerv. Mental Dis. $166,562-570$.

Regier, D.A., Farmer, M.E., Rae, D.S., Locke, B., Keith, S.J., Judd, L.L. and Goodwin, F.K. (1990) Comorbidity of mental disorders with alcohol and other drug abuse: results from the epidemiological catchment area study. J. Am. Med. Assoc. 264, 2511-2519.

Research Triangle Institute. (1994) Software for Survey Data Analysis (SUDAAN), Version 5.30. Research Triangle Institute, Research Triangle Park, NC.

Robins, L.N., Helzer, J.E., Croughhan, J. and Ratcliff, K.L. (1981) National Institute of Mental Health Diagnostic Interview Schedule: Its history, characteristics and validity. Arch. Gen. Psychiat. 38, 381-389.

Robins, L.N., Locke, B.Z. and Regier, D.A. (1991) An overview of psychiatric disorders in America. In: Psychiatric Disorders in America: The Epidemiologic Catchment Area Study, (Robins, L.N. and Regier, D.A., eds.), pp. 328-366. The Free Press, New York.

Ross, H.E., Glaser, F.B. and Germanson, T. (1988) The prevalence of psychiatric disorders in patients with alcohol and other drug problems. Arch. Gen. Psychiat. 45, 1023-1031.

Rounsaville, B.J., Dolinski, Z.S., Babor, T.F. and Meyer, R.E. (1987) Psychopathology as a predictor of treatment outcome in alcoholics. Arch. Gen. Psychiat. 44, 505-513.

Rounsaville, B.J., Kosten, T.R., Weissman, M.M. and Kleber, H.D. (1991) Psychiatric disorders in relatives of probands with opiate addiction. Arch. Gen. Psychiat. 48, 33-42.

Roy, A., DeJong, J., Lamparski, D., Adinoff, B., George, T., Moore, V., Gamett, D., Kerich, M. and Linnoila, M. (1991a) Depression among alcoholics: relationship to clinical and cerebrospinal fluid variables. Arch. Gen. Psychiat. 48, 428-432.

Roy, D., Lamparski, D. and Adinoff, B. (1991b) Mental disorders among alcoholics: relationship to age of onset and cerebrospinal fluid neuropeptides. Arch. Gen. Psychiat. 48, 423-427.

Wittchen, H.U. and Kessler, R.C. (1991) The University of Michigan Composite International Diagnostic Interview. University of Michigan Survey Research Center, Minneapolis, MN.

Wolf, A.W., Schubert, D.S.P., Patterson, M.B. and Grande, T.P. (1988) Associations among major psychiatric diagnoses. J. Consult. Clin. Psychol. 56, 292-294.

Woodruff, R.A., Guze, S.B., Clayton, P.J. and Carr, D. (1973). Alcoholism and depression. In: Alcoholism and Affective Disorders, (Goodwin D.W. and Erickson, C.K., eds.), pp. 46-59. Spectrum Publications, New York. 